\title{
Implications of the introduction of laboratory demand management at primary care clinics in South Africa on laboratory expenditure
}

\begin{tabular}{|c|c|}
\hline \multicolumn{2}{|l|}{$\begin{array}{l}\text { Authors: } \\
\text { Ozayr H. Mal } \\
\text { Ruth Lekalak }\end{array}$} \\
\hline \multicolumn{2}{|c|}{$\begin{array}{l}\text { Affiliations: } \\
{ }^{1} \text { Discipline of Public Health } \\
\text { Medicine, University of } \\
\text { KwaZulu-Natal, Durban, } \\
\text { South Africa }\end{array}$} \\
\hline \multicolumn{2}{|c|}{$\begin{array}{l}{ }^{2} \text { Clinical Microbiologist, } \\
\text { University of Limpopo, } \\
\text { Polokwane, South Africa }\end{array}$} \\
\hline \multicolumn{2}{|c|}{$\begin{array}{l}\text { 3Senior Technical Advisor, } \\
\text { National Department of } \\
\text { Health, Pretoria, Gauteng, } \\
\text { South Africa }\end{array}$} \\
\hline \multicolumn{2}{|c|}{$\begin{array}{l}{ }^{4} \text { Data and Logistics Manager, } \\
\text { National Health Laboratory } \\
\text { Service, Johannesburg, } \\
\text { Gauteng, South Africa }\end{array}$} \\
\hline \multicolumn{2}{|c|}{$\begin{array}{l}\text { Correspondence author and } \\
\text { email: } \\
\text { Ozayr Mahomed } \\
\text { mahomedo@ukzn.ac.za }\end{array}$} \\
\hline $\begin{array}{l}\text { Dates: } \\
\text { Received: } 01 \mathrm{~J} \\
\text { Accepted: } 23 \\
\text { Published: } 18\end{array}$ & $\begin{array}{l}\text { uly } 2015 \\
\text { Mec. } 2015 \\
\text { Mar. } 2016\end{array}$ \\
\hline \multicolumn{2}{|c|}{$\begin{array}{l}\text { How to cite this article: } \\
\text { Mahomed OH, Lekalakala R, } \\
\text { Asmall S, Cassim N. } \\
\text { Implications of the introduction } \\
\text { of laboratory demand } \\
\text { management at primary care } \\
\text { clinics in South Africa on } \\
\text { laboratory expenditure. Afr J } \\
\text { Lab Med. 2016;5(1), Art. \#339, } \\
6 \text { pages. http://dx.doi. } \\
\text { org/10.4102/ajlm.v5i1.339 }\end{array}$} \\
\hline \multicolumn{2}{|c|}{$\begin{array}{l}\text { Copyright: } \\
\text { (c) 2016. The Authors. } \\
\text { Licensee: AOSIS. This work } \\
\text { is licensed under the } \\
\text { Creative Commons } \\
\text { Attribution License. }\end{array}$} \\
\hline \multicolumn{2}{|l|}{ Read online: } \\
\hline 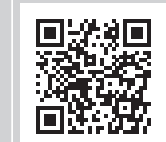 & $\begin{array}{l}\text { Scan this QR } \\
\text { code with your } \\
\text { smart phone or } \\
\text { mobile device } \\
\text { to read online. }\end{array}$ \\
\hline
\end{tabular}

Background: Diagnostic health laboratory services are regarded as an integral part of the national health infrastructure across all countries. Clinical laboratory tests contribute substantially to health system goals of increasing quality of care and improving patient outcomes.

Objectives: This study aimed to analyse current laboratory expenditures at the primary healthcare (PHC) level in South Africa as processed by the National Health Laboratory Service and to determine the potential cost savings of introducing laboratory demand management.

Methods: A retrospective cross-sectional analysis of laboratory expenditures for the 2013/2014 financial year across 11 pilot National Health Insurance health districts was conducted. Laboratory expenditure tariff codes were cross-tabulated to the PHC essential laboratory tests list (ELL) to determine inappropriate testing. Data were analysed using a Microsoft Access database and Excel software.

Results: Approximately R35 million South African Rand (10\%) of the estimated R339 million in expenditures was for tests that were not listed within the ELL. Approximately $47 \%$ of expenditure was for laboratory tests that were indicated in the algorithmic management of patients on antiretroviral treatment. The other main cost drivers for non-ELL testing included full blood count and urea, as well as electrolyte profiles usually requested to support management of patients on antiretroviral treatment.

Conclusions: Considerable annual savings of up to $10 \%$ in laboratory expenditure are possible at the PHC level by implementing laboratory demand management. In addition, to achieve these savings, a standardised PHC laboratory request form and some form of electronic gatekeeping system that must be supported by an educational component should be implemented.

\section{Introduction}

Diagnostic health laboratory services are regarded as an integral part of the national health system across all countries and have an important role in the continuum of care. Laboratory testing provides access to screening of asymptomatic individuals at risk for developing disease, early detection of diseases and diagnostic confirmation; provides information on patients' prognosis; assists with planning appropriate disease management strategies and monitoring patients' response to treatment; and plays a pivotal role in ensuring patient safety by identifying hospital-acquired infections and other potential health related adverse events. ${ }^{1}$

The National Health Laboratory Service (NHLS) provides diagnostic laboratory services for the South African public health sector through over 300 laboratories across the nine provinces, thereby achieving $80 \%$ population coverage. ${ }^{2}$ The NHLS is reimbursed by the Provincial Departments of Health on a fee-for-service billing arrangement. ${ }^{2}$ Through this payment mechanism, laboratory tests are itemised as tariff codes on an invoice, for example, tariff code 2210 denotes the haemoglobin test. These funds are obtained from the provincial equitable share portion of the national health budget.

Expenditures for laboratory services have increased by 45\% from R3.1 billion South African Rand in financial year (FY) 2010/2011 (01 April 2010 to 31 March 2011) to R4.5 billion by FY 2013/2014 (01 April 2013 to 31 March 2014). ${ }^{3}$ This was because of increases in laboratory test volumes from 80.2 million tests in FY 2011/2012 to 81.1 million in FY 2012/2013 ${ }^{4}$ and approximately 86 million 
tests in FY 2013/2014. ${ }^{2}$ The sharp increases in expenditures and test volumes in FY 2013/2014 can be attributed to growth in priority test volume. Priority tests for patients living with HIV, tuberculosis and cervical cancer accounted for $16 \%$ of total test volume ${ }^{2}$ in FY 2013/2014. There was a 144\% increase in the volume of GeneXpert MTB/RIF assays, as well as a $27 \%$ increase in HIV viral load testing. ${ }^{3}$ The GeneXpert MTB/RIF assay replaced the auramine smear for diagnosis of tuberculosis during this time period. There was a large difference in the price per test; auramine smears cost R24.34, whereas the GeneXpert MTB/RIF assay cost R172.85 as of December 2013.

The volume of laboratory testing is anticipated to increase with the introduction of general practitioners as care providers for patients at the primary healthcare (PHC) level, because general practitioners are expected to order additional laboratory tests that were not previously requested under nurse-based PHC services. Furthermore, a renewed focus has been placed on integrated clinical services at the $\mathrm{PHC}$ level ${ }^{5}$ and the introduction of algorithms to appropriately manage patient conditions. ${ }^{6}$ This is likely to further increase the volume of tests requested, thereby increasing the total expenditures of the public health system.

Demand management aims to improve the requesting of appropriate laboratory tests and results in reductions in public health expenditures without affecting clinical outcomes. ${ }^{7}$ The first step to implementing demand management involves defining what constitutes an 'inappropriate' request, based on some form of agreed-upon guidance. ${ }^{7}$ For example, this may involve standardising the repertoire of tests that may be requested by level of care, namely, PHC and hospital services. ${ }^{7}$ Similarly, evidence-based laboratory medicine involves eliminating laboratory tests with no clinical value and introducing new laboratory tests where evidence proves their efficacy and effectiveness. ${ }^{8}$ The implementation of this approach requires a pathologist-driven laboratory service that utilises context-appropriate evidence to guide testing and reduce public health expenditures.

The South African National Department of Health has proposed a demand-management system in the form of an essential laboratory tests list (ELL) to promote appropriate and cost effective usage of laboratory services at PHC facilities without having a negative effect on patient outcomes. The ELL includes the minimum set of tests that should be performed to offer comprehensive services at the PHC level. ${ }^{9}$ In determining the ELL for South Africa, the World Health Organization criteria for the usefulness and clinical relevance of tests that influence diagnosis and patient management were considered..$^{9}$ Additionally, the ELL requires that a single test be used, rather than multiple tests, if the single test provides adequate diagnostic information. ${ }^{9}$ For example, on the ELL, the alanine transaminase test is substituted for the liver function panel test, as the alanine transaminase test provides the same diagnostic value without affecting patient outcomes. Furthermore, the laboratory tests included on the ELL were aligned to the national South
African standard treatment guidelines, ${ }^{10}$ including the PHC clinical algorithms that were introduced as a clinical supportive management component of the integrated chronic disease management mode. ${ }^{5}$

The aims of this study were to analyse current expenditures and the profile of laboratory tests currently requested at the PHC level. In addition, we sought to determine the potential cost savings that could be achieved by the public health sector through the introduction of the demand-managementbased ELL.

\section{Research method and design}

This was a retrospective cross-sectional analysis of PHC laboratory expenditure for the FY 2013/2014 period across 11 National Health Insurance (NHI) pilot districts. Data on district and facility level expenditures for the Amajuba, City of Tshwane Metro, Dr Kenneth Kaunda, Eden, Gert Sibande, OR Tambo, Pixley ka Seme, Thabo Mofutsanyana, Umgungundlovu, Umzinyathi and Vhembe districts were extracted from the NHLS Corporate Data Warehouse. The extracted data fields included customer account information, laboratory information, system location codes used to identify health facilities, tariff codes used for billing purposes (to identify the investigation(s) performed), annual test volumes and expenditures. All expenditure data were reported in South African Rand.

The ELL defines the laboratory tests that could be requested at PHC facilities by nursing staff or general practitioners. For example, nurses can request thyroid stimulating hormone tests; however, general practitioners can also request a free thyroxine 4 test. Amongst other tests, the ELL included haemoglobin, HIV viral load, GeneXpert for tuberculosis, cluster definition 4 (CD4) count, HIV DNA PCR for infants, sputum and urine microscopy, smear, culture and sensitivity, total cholesterol and total triglycerides, prostatic specific antigens, cervical smears and glycated haemoglobin (HbA1c). Tests not on the ELL for primary healthcare included full blood count, urea and electrolytes, HIV serology, liver function tests, drug levels for carbamezapine and tegretol, endocrine tests such as thyroid profiles and follicule stimulating hormones and luteinising hormone levels, arthritis screening, anti-nuclear factors and other immunological tests.

Each ELL test was mapped to one or more NHLS tariff code(s) from the expenditure data. A one-to-one or a one-to-many relationship exists between an ELL test and the tariff code(s) used by the NHLS. For example, the CD4 test represents a one-to-one relationship. However, the $\mathrm{C}$-reactive protein test has a one-to-many relationship, as different tariff codes are used based on the laboratory methodology, for example, qualitative versus quantitative test. Furthermore, some ELL tests follow a diagnostic cascade, whereby based on an initial result, a subsequent investigation is performed, such as microscopy, culture and sensitivity. Additionally, ELL tests were grouped into logical test baskets, for example, lipogram for cholesterol and triglycerides. 
For the expenditure analysis, a Microsoft Access 2010 database (Microsoft Corporation, Redmond, Washington, United States) was used and the expenditures and ELL mapping list were imported as tables. The expenditure tariff codes were reported with the ELL test by creating a relationship between the two tables. Queries were developed to report on tariff code expenditures based on the ELL test.

\section{Results}

\section{Test volumes and expenditures by health district}

Approximately 4.5 million tests accounted for approximately R339 million in laboratory expenditures for diagnostic laboratory tests at the $\mathrm{PHC}$ facilities in the 11 districts during the FY 2013/2014 study period (Table 1). PHC facilities within the City of Tshwane (Gauteng) accounted for the highest proportion of test volume and laboratory expenditures, followed by clinics within the OR Tambo district (Eastern Cape) and Umgungundlovu district (KwaZulu-Natal).

\section{Total expenditures on ELL and non-ELL laboratory tests}

Of all laboratory expenditures for FY 2013/2014, 21 tests were responsible for $\sim 92 \%$ (R310 million) of the total (Table 2). Laboratory tests for patients living with HIV were responsible for $\sim 47 \%$ of all expenditures, of which HIV viral load accounted for $\sim 32 \%$ of expenditures, CD4 for $\sim 10 \%$ and HIV DNA PCR for infants, $\sim 6 \%$. Laboratory tests for tuberculosis diagnosis accounted for $\sim 21 \%$ of the expenditure, including tuberculosis microscopy $(\sim 2 \%)$, GeneXpert $(\sim 18 \%)$ and tuberculosis culture $(\sim 1 \%)$. Non-ELL tests such as the full blood count and the urea and electrolyte tests were responsible for $5 \%$ of expenditure (R16 million).

TABLE 1: Test volumes and laboratory expenditures for primary healthcare facilities within 11 National Health Insurance pilot districts, South Africa, 2013-2014. $\dagger$

\begin{tabular}{|c|c|c|c|c|}
\hline National Health Insurance pilot district & Number of tests & Percentage of total number of tests (\%) & Expenditure (ZAR) & Percentage of total expenditure (\%) \\
\hline Amajuba & 204014 & 5 & R16 957104 & 5 \\
\hline City of Tshwane Metro & 960437 & 22 & R70 207965 & 21 \\
\hline Dr Kenneth Kaunda & 385380 & 9 & R30 002610 & 9 \\
\hline Eden & 286446 & 6 & R18 725978 & 6 \\
\hline Gert Sibande & 481014 & 11 & R34 079371 & 10 \\
\hline OR Tambo & 544269 & 12 & R42 377609 & 12 \\
\hline Pixley Ka Seme & 161371 & 4 & R11 449909 & 3 \\
\hline Thabo Mofutsanyana & 337386 & 8 & R31 073208 & 9 \\
\hline Umgungundlovu & 484247 & 11 & R42 361325 & 12 \\
\hline Umzinyathi & 158848 & 4 & R12 123605 & 4 \\
\hline Vhembe & 443529 & 10 & R29 958630 & 9 \\
\hline Total & 4446941 & 100 & R339 317313 & 100 \\
\hline
\end{tabular}

ZAR, South African Rand.

$\dagger$, Analysis included data for financial year 2013/2014, which began 01 April 2013 and ended 31 March 2014.

TABLE 2: Laboratory tests with the highest expenditures across the 11 National Health Insurance pilot districts, South Africa, 2013-2014. $\dagger$

\begin{tabular}{|c|c|c|c|}
\hline Test description & Expenditure (ZAR) & Percentage of total expenditure $\$(\%)$ & Cumulative percentage $\S(\%)$ \\
\hline HIV viral load & 107094208 & 31.6 & 31.6 \\
\hline GeneXpert for MTB/RIF & 61937837 & 18.3 & 49.9 \\
\hline CD4 & 33685531 & 9.9 & 59.8 \\
\hline HIV DNA PCR & 19646244 & 5.8 & 65.6 \\
\hline Creatinine & 15596873 & 4.6 & 70.2 \\
\hline Full blood count $\uparrow$ & 9807196 & 2.9 & 73.1 \\
\hline Alanine transaminase & 9136749 & 2.7 & 75.8 \\
\hline Urea and electrolytes & 6989505 & 2.1 & 77.9 \\
\hline Pap smear & 6668283 & 2.0 & 79.9 \\
\hline Tuberculosis direct (auramine) & 5939449 & 1.8 & 81.7 \\
\hline Hepatitis A IgG & 5027926 & 1.5 & 83.2 \\
\hline Rapid plasmin reagin & 4888999 & 1.4 & 84.6 \\
\hline Tuberculosis culture & 4242050 & 1.3 & 85.9 \\
\hline Rhesus factor & 3629905 & 1.1 & 87.0 \\
\hline Haemaglobin & 2935956 & 0.9 & 88.8 \\
\hline Thyroid stimulating hormone & 2597554 & 0.8 & 89.6 \\
\hline Glycated haemoglobin & 2110422 & 0.6 & 90.2 \\
\hline Tryglyceride & 1967680 & 0.6 & 90.8 \\
\hline Aspartate transaminase & 1805915 & 0.5 & 91.3 \\
\hline Prostatic specific antigen & 1764142 & 0.5 & 91.8 \\
\hline Total & 310663827 & 91.8 & 91.8 \\
\hline
\end{tabular}

MTB/RIF, Mycobacterium tuberculosis/Rifampicin; IgG, Immunoglobulin G; ELL, essential laboratory list; PHC, primary healthcare; ZAR, South African Rand.

$\dagger$, Analysis included data for all laboratory tests (both tests on the ELL and tests not on the ELL) billed in financial year 2013/2014, which began 01 April 2013 and ended 31 March 2014; $\$$, Percentage of total laboratory expenditure (R339 317313 ); $\S$, Cumulative percentage of total expenditure; $\uparrow$, These tests were not listed in the ELL for PHC services and were thus considered 'inappropriate'. 
TABLE 3: Laboratory expenditures for essential laboratory list (ELL) tests and non-ELL tests within the 11 National Health Insurance pilot districts, South Africa, 2013-2014. $\dagger$

\begin{tabular}{|c|c|c|c|c|c|}
\hline NHI pilot district & $\begin{array}{c}\text { ELL test } \\
\text { expenditure (ZAR) }\end{array}$ & $\begin{array}{l}\text { ELL percentage } \\
\text { of district total } \\
\text { expenditure }(\%)\end{array}$ & $\begin{array}{c}\text { Non-ELL } \\
\text { test expenditure } \\
\text { (ZAR) (\%) }\end{array}$ & $\begin{array}{l}\text { Non-ELL percentage } \\
\text { of district total } \\
\text { expenditure (\%) }\end{array}$ & $\begin{array}{c}\text { Total district } \\
\text { expenditure (ZAR) }\end{array}$ \\
\hline Amajuba & 15703295 & 93 & 1253809 & 7 & 16957104 \\
\hline City of Tshwane Metro & 61977231 & 88 & 8230733 & 12 & 70207965 \\
\hline Dr Kenneth Kaunda & 26806032 & 89 & 3196577 & 11 & 30002610 \\
\hline Eden & 16934366 & 90 & 1791612 & 10 & 18725978 \\
\hline Gert Sibande & 29460294 & 86 & 4619077 & 14 & 34079371 \\
\hline Pixley Ka Seme & 9944644 & 87 & 1505265 & 13 & 11449909 \\
\hline Thabo Mofutsanyana & 29494934 & 95 & 1578274 & 5 & 31073208 \\
\hline Umgungundlovu & 37962309 & 90 & 4399017 & 10 & 42361325 \\
\hline Umzinyathi & 10976833 & 91 & 1146772 & 9 & 12123605 \\
\hline Vhembe & 26309844 & 88 & 3648786 & 12 & 29958630 \\
\hline Total expenditures & 304280306 & - & 35037007 & - & 339317314 \\
\hline Total percentage of expenditures (\%) & 90 & - & 10 & - & 100 \\
\hline
\end{tabular}

NHI, National Health Insurance; ELL, essential laboratory list; ZAR, South African Rand.

$\dagger$, Analysis included data for all laboratory tests (both tests on the ELL and tests not on the ELL) billed in financial year 2013/2014, which began 01 April 2013 and ended 31 March 2014.

\section{Expenditure on non-ELL tests by district}

Across the 11 NHI pilot districts, 10\% (R35 million) of laboratory expenditures at PHC facilities were for tests that were not included on the ELL (Table 3). In five districts, including Gert Sibande, Pixley Ka Seme, Vhembe, City of Tshwane and Dr Kenneth Kaunda, the proportion of tests not included on the ELL exceeded $10 \%$ of the PHC's laboratory expenditure.

\section{Profile of the non-ELL tests processed}

Of all the laboratory tests not included on the ELL, 21 tests accounted for 91\% (R31 million) of the total non-ELL laboratory expenditures (R35 million) (Figure 1). Of these tests, the full blood count $(28 \%)$ and urea and electrolyte $(20 \%)$ tests were the main cost drivers for non-ELL tests. The third main contributor was the different components of the liver function test, which together accounted for $17 \%$ of expenditures for non-ELL tests (aspartate transaminase, $5 \%$; total protein, $2 \%$; albumin, $4 \%$; total bilirubin, $3 \%$; direct bilirubin, 2\%; and lactate dehydrogenase, $1 \%$ ). Rhesus factor laboratory tests accounted for $10 \%$ of the non-ELL laboratory expenditures. The remaining non-ELL tests accounted for $9 \%$ of non-ELL expenditure.

\section{Discussion}

This retrospective analysis of laboratory expenditure data for FY 2013/2014 indicated that facilities within the $11 \mathrm{NHI}$ pilot districts accounted for approximately R339 million of all PHC facility expenditures for diagnostic laboratory tests. The City of Tshwane had the highest proportion for test volume and laboratory expenditure, followed by facilities within the OR Tambo and Umgungundlovu districts. Diagnostic tests for HIV and tuberculosis were the main cost drivers for laboratory expenditure. Of the estimated R339 million total, approximately R35 million (10\%) were for non-ELL tests. Full blood count, urea and electrolyte profiles, as well as liver function tests usually done to support the holistic management of patients on ART, were the main cost drivers for non-ELL tests.

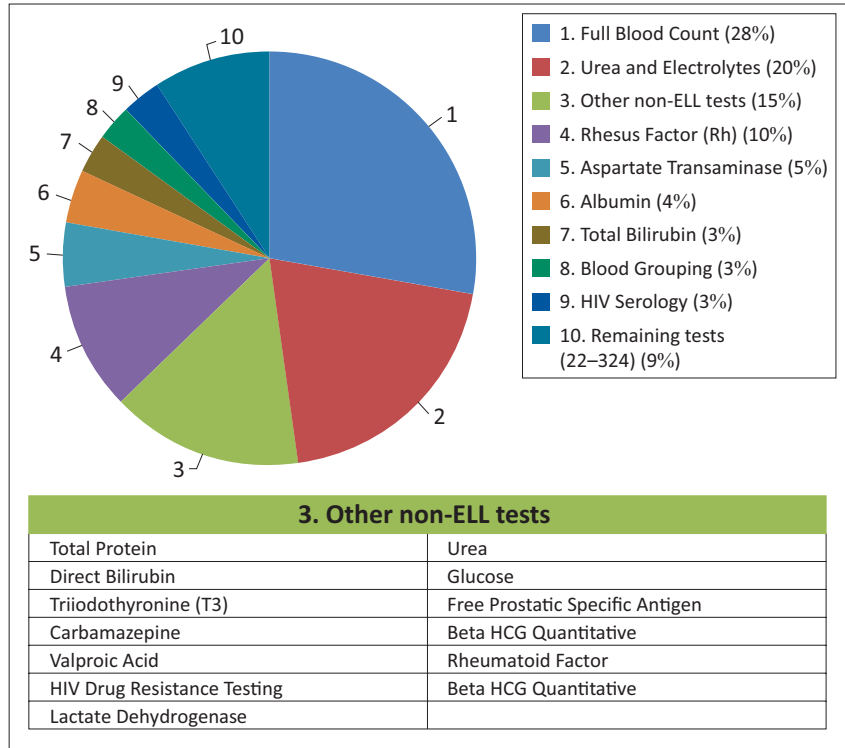

ELL, essential laboratory list; PHC, primary healthcare; HCG, human chorionic gonadotropin. FIGURE 1: Non-ELL expenditures within the 11 National Health Insurance pilot districts, South Africa, 2013-2014. Analysis included data for the 21 most common tests not on the ELL that were billed in financial year 2013/2014, which began on 01 April 2013 and ended 31 March 2014. These 21 tests represented 91\% of 'inappropriate' (non-ELL) laboratory expenditures for the PHC facilities within the $11 \mathrm{NHI}$ pilot districts.

Public health expenditures overall are expected to increase by an average of $7.9 \%$ between FY 2014/2015 and FY 2016/2017. ${ }^{6}$ Laboratory expenditures are expected to increase by an average of $17.7 \%$ during the same time period. This is likely to increase budgetary pressures on an already cashstrapped public health sector and, in particular, on the NHLS. However, despite these financial constraints, the NHLS is expected to provide or maintain the same standard of service.

Laboratory, patient, healthcare provider and systemic factors are often cited as potential reasons for 'inappropriate laboratory tests requests'. ${ }^{7}$ Laboratory factors include prolonged turn-around-times, inability to access results due to the lack of information systems, laboratory request forms that enable the request of a panel test rather than an individual test and the availability of an open-ended, 'other tests' box.? 
Healthcare providers may inappropriately request tests because of inexperience, inadequate understanding or lack of awareness regarding the guidelines or protocols of management, a lack of information about the unit cost of each test, or routine practice. ${ }^{11}$ Additionally, the poor filing systems within health facilities often result in duplicate test requests. ${ }^{7}$

In 2008, the Carter Review noted that $25 \%$ of pathology tests conducted in the United Kingdom National Health Service were unnecessary ${ }^{7}$ and the implementation of demand management would conservatively result in a $20 \%$ savings in laboratory expenditures. ${ }^{12}$ Our study found that an average of $10 \%$ of the laboratory test expenditures at the PHC level were for non-ELL tests. If use of the demand-management-based ELL were extended to district, regional and tertiary hospitals, the savings would be in line with the Carter estimate. A conservative estimate based on the $10 \%$ savings applied to all 3400 PHC facilities across 52 NHLS districts would result in an annual savings of R400 million to the health sector.

\section{Recommendations}

Currently, laboratories are required to perform all tests requested by the clinician and/or nursing staff, resulting in over-utilisation of services. To address inappropriate use of laboratory tests (i.e., non-ELL tests) across South Africa by PHC facilities, three key initiatives are proposed.

The first initiative is the development of a national ELL. This would require the standardisation of typical clinical laboratory tests per level of healthcare, whilst taking into consideration local demographic and epidemiological factors. ${ }^{9}$ The second initiative would be to support the ELL by developing a dedicated PHC laboratory request form that lists only tests appropriate for the PHC level. Clinicians and nurses would thus be able to select only from amongst tests on the ELL. An important aspect of the PHC request form design would be to remove the 'other tests' box, which enables clinicians to request any investigation. The first two initiatives should, in turn, be supported by the third: electronic gatekeeping to reject tests that are inappropriately requested (not on the ELL). However, in order to achieve this initiative, all PHC health facilities would be required to use a health information system, including an order entry module with built-in rules to avoid inappropriate ordering.

Whilst the above measures may help to reduce inappropriate laboratory test requests, appropriate education initiatives directed at health service providers would also be required to support these interventions. These educational sessions should provide guidance on appropriate laboratory testing based on clinical guidelines and evidence-based laboratory medicine recommendations to ensure that specimens are collected in the correct manner. ${ }^{7}$

\section{Limitations}

This study was a retrospective cross-sectional study and used secondary data on expenditures; it was thus dependent on the accuracy of the data entered into the information systems.
It was not possible to differentiate whether tests were coded accurately or combined when multiple individual tests were ordered. In addition, the study was limited to NHI health districts and the results may not be representative of other health districts in South Africa. Finally, the study focused on one aspect for potential savings. Additional studies may be required to investigate other aspects of appropriate utilisation of the diagnostic laboratory services.

\section{Conclusion}

This study demonstrated that considerable potential savings of up $10 \%$ in laboratory expenditure are possible following the introduction of an ELL at the PHC level, in addition to further laboratory demand management interventions.

\section{Acknowledgements Competing interests}

The authors declare that they have no financial or personal relationship(s) that may have inappropriately influenced them in writing this article.

\section{Sources of support}

The authors wish to thank Sue Candy and Manfred Tepper at the National Health Laboratory Service Corporate Data Warehouse for their assistance and support in extracting the health facility expenditure data.

\section{Authors' contributions}

O.H.M. (University of KwaZulu-Natal) drafted the article and conducted the analysis. R.L. (University of Limpopo) provided technical input on the draft article. S.A. (National Department of Health) provided editorial comments and technical input on the essential laboratory list. N.C. (National Health Laboratory Service) retrieved the data, conducted the preliminary analysis and drafted the article.

\section{References}

1. The Lewin Group, Inc. The value of laboratory screening and diagnostic tests for prevention and health care improvement. Washington: American Clinical Laboratory Association and Advanced Medical Technology Association (AdvaMed); 2009.

2. National Health Laboratory Service. Annual Report 2014/15. Johannesburg National Health Laboratory Service; 2015.

3. National Treasury. Estimates of provincial revenue and expenditure [document on the Internet]. c2012 [cited 2015 March 11]. Available from: http://www.treasury. gov.za/documents/provincial\%20budget/2012/4.\%20Estimates\%20of\%20 Pov.za/documents/provincial\%20budget/2012/4.\%20Estimates\%20of\%20 pdf.

4. National Health Laboratory Service. Annual Report-2012-13. Johannesburg National Health Laboratory Service; 2013.

5. Mahomed O, Asmall S, Freeman M. An integrated chronic disease management model: a diagonal approach to health system strengthening in South Africa. J Healthcare Poor Underserved. 2014 Nov;25(4):1723-1729. http://dx.doi. org/10.1353/hpu.2014.0176

6. National Department of Health. Primary Care 101. Pretoria: Knowledge Translation Unit, National Department of Health; 2008.

7. Fryer A, Smellie W. Managing demand for laboratory tests: a laboratory toolkit. J Clin Pathol. 2013 Jan;66(1):62-72. http://dx.doi.org/10.1136/jclinpath-2011200524

8. Horvath A. From evidence to best practice in laboratory medicine. Clin Biochem Rev. 2013 Aug;34(2):47-60. 
9. World Health Organization. Laboratory services for primary health care: requirements for essential clinical laboratory tests. Geneva: World Health requirements for essential clinical laboratory tests.
Organization, Health Laboratory Technology Unit; 1998.

10. National Department of Health. Standard treatment guidelines and essential medicines list for South Africa, Primary Health Care level. Pretoria: National Department of Health; 2008.
11. Nardi R, Berti F, Fabbri L, et al. Toward a sustainable and wise healthcare approach: potential contributions from hospital Internal Medicine Departments to reducing inappropriate medical spending. Ital J Med. 2013;7(2):65-81. http://dx.doi. org/10.4081/itjm.2013.65

12. Department of Health. Report of the second phase of the review of the NHS Pathology Services in England. London: Department of Health; 2008. 